Jurnal Informatika dan Rekayasa Perangkat Lunak (JATIKA)
Vol. 1, No. 2, Desember 2020, 203-214

\title{
APLIKASI VIRTUAL TOUR ISLAMIC CENTER BERBASIS ANDROID
}

\author{
Rindu Roro Rembulan ${ }^{1}$, Dyah Ayu Megawaty ${ }^{2}$ \\ S1 Informatika, Universitas Teknokrat Indonesia
}

\begin{abstract}
rindurororembulan@gmail.com ${ }^{1}$,dyahayumegawaty@teknokrat.ac.id ${ }^{2}$
\end{abstract}
\begin{abstract}
Received: (9 November 2020)Accepted: (30 Desember 2020) Published: (31 Desember 2020)
\end{abstract}
\begin{abstract}
developers Smartphone software have been expanding variety of technologies, one example is thetechnology Virtual Tour (VR). Technology Virtual Tour or also called panoramic a tour is a simulation of a place that actually exists, consisting of a collection of 360 photos, panoramic photos, a collection of images connected by hyperlinks, 3-dimensional models or videos. Virtual Tour has been widely used as an effective promotional tool, especially in tourism through interactive media. Currently the Islamic center has not been able to maximize visitor interest because it still uses conventional media such as brochures and banner advertisements as well as locations that are far from urban areas, so there has not been a significant increase in the local area. The research conducted aims to build an android mobile based application by utilizing technology virtual The tour is expected to increase the promotional value and attraction of visitors, as well as introduce the Islamic Center from outside the West Tulang Bawang district in the form of a $360^{\circ}$ panoramic video object. The development method in this study uses Luther's model of Multimedia Development Life Cycle (MDLC). As for testing the system, the author uses thequality standard International Organization of Standardization (ISO) 25010, the aspects to be tested areaspects. functional Suitability, aspects Operability, andaspects Transferability. This application has been tested using ISO 25010, the aspects tested areaspects functional Suitability gets a score of 100\%, theaspect Operability gets a score of $94 \%$ and theaspect Transferability gets a score of $100 \%$ and the average execution time is 1.0364 seconds. From the overall testing of ISO 25010, we get an average total score of 95\% or have a very good scale.
\end{abstract}

Keywords : Augmented reality, ISO 25010, MDLC, Panoramic.

\section{Abstrak}

Para developer software smartphone telah mengembang berbagai teknologi, salah contohnya adalah teknologi Virtual Tour (VR). Teknologi Virtual Tour atau disebut juga panoramic tour merupakan sebuah simulasi dari suatu tempat yang benar-benar ada, terdiri dari kumpulan foto $360^{\circ}$, foto panorama, kumpulan gambar yang terhubung oleh hyperlink, model 3 dimensi ataupun video. Virtual Tour telah banyak digunakan secara luas sebagai alat promosi yang efektif khususnya dibidang pariwisata melalui media interaktif. Saat ini Islamic center belum dapat memaksimalkan minat pengunjung dikarenakan masih menggunakan media konvensional seperti brosur dan iklan banner serta lokasi yang jauh dari perkotaan, sehingga belum terlihat peningkatan bagi wilayah setempat secara signifikan. Penelitian yang dilakukan bertujuan untuk membangun aplikasi berbasis mobile android dengan memanfaatkan teknologi Virtual Tour yang diharapkan dapat meningkatkan nilai promosi dan daya tarik pengunjung, serta memperkenalkan Islamic Center dari luar kabupaten Tulang Bawang Barat secara virtual berupa obyek video panorama $360^{\circ}$. Metode pengembangan pada penelitian ini menggunakan Multimedia Development Life Cycle (MDLC) model Luther. Sedangkan untuk pengujian sistemnya, penulis menggunakan standar kualitas International Organization of Standardzation (ISO) 25010, adapun aspek yang akan diuji adalah aspek Functional Suitability, aspek Operability, dan aspek Transferability. Aplikasi ini sudah diuji menggunakan ISO 25010, aspek yang diuji adalah aspek Functional Suitability mendapatkan skor 100\%, aspek Operability mendapatkan skor $94 \%$ dan aspek Transferability mendapatkan skor $100 \%$ serta waktu rata-rata eksekusi 1,0364 detik. Dari keseluruhan pengujian ISO 25010 mendapatkan skor total rata-rata $95 \%$ atau mempunyai skala sangat baik.

Kata Kunci : Augmented reality, ISO 25010, MDLC, Panoramic. 
To cite this article:

Rindu Roro Rembulan, Dyah Ayu Megawaty. (2020). APLIKASI VIRTUAL TOUR ISLAMIC CENTER BERBASIS ANDROID, Vol(1) No(2), 203-214.

\section{PENDAHULUAN}

Seiring dengan perkembangan teknologi yang semakin maju, berbagai macam teknologi telah diciptakan untuk berbagai keperluan dan pada berbagai bidang ilmu. Terutama dalam bidang informasi, edukasi dan komunikasi, adapun dengan perkembangan ini dapat menimbulkan banyak dampak positif bagi pemakai atau user. Kebutuhan informasi dalam media pengenalan masih banyak menggunakan cara konvensional dan tidak memadukan unsur - unsur teknologi moderen, salah satu bentuk penyampaian informasi atau pengenalan suatu obyek wisata yang dapat digunakan adalah dengan menggunakan teknologi Virtual Tour (Maulana, dkk., 2020)

Virtual Tour atau disebut juga panoramic tour merupakan sebuah simulasi dari suatu tempat yang benarbenar ada, terdiri dari kumpulan foto-360, foto panorama, kumpulan gambar yang terhubung oleh hyperlink, model 3 dimensi ataupun video (Wicaksono, dkk., 2017). Melalui aplikasi Virtual Tour dapat membantu menyajikan panorama dari suatu tempat yang sulit diakses bagi masyarakat. Virtual Tour telah banyak digunakan secara luas sebagai alat promosi yang efektif khususnya dibidang pariwisata melalui media interaktif (Yuliana dan Lisdianto, 2017).

Islamic Center sebagai salah satu icon di kabupaten Tulang Bawang Barat yang sangat dibanggakan oleh masyarakat setempat. Islamic Center berlokasi di Jl. Raya Panaragan Jaya, kelurahan Panaragan Jaya, kabupaten Tulang Bawang Barat, provinsi Lampung. Bangunan ini diresmikan oleh Menteri Agama Republik Indonesia yaitu Dr. Hi. Lukman Hakim Saifudin pada tanggal 11 Oktober 2016. Meskipun tujuan utama pembangunannya adalah sebagai tempat kegiatan keagamaan (tempat beribadah umat Islam) dan kepentingan adat, tetapi Islamic Center Tulang Bawang Barat juga kerap mengadakan kegiatan lain seperti prosesi wisuda, resepsi pernikahan, prewedding, pementasan, festival, workshop, seminar dan pameran. Akan tetapi masyarakat memiliki makna lain bagi keberadaan bangunan tersebut, yaitu sebagai ruang yang dapat dijadikan tempat wisata (Islamic Center Kebanggaan Masyarakat Tubaba, 2019).

Dari hasil wawancara dengan sekretariat Islamic Center Tulang Bawang Barat, saat ini Islamic center belum dapat memaksimalkan minat pengunjung dikarenakan masih menggunakan media konvensional seperti brosur dan iklan banner serta lokasi yang jauh dari perkotaan, sehingga belum terlihat peningkatan bagi wilayah setempat secara signifikan. Berbagai upaya telah dilakukan oleh masyarakat dan pemerintah namun belum bisa mengatasi permasalahan tersebut, maka perlu adanya upaya yang dibutuhkan dari media informasi sekaligus media promosi untuk meningkatkan minat pengunjung dari luar kabupaten (Rahman, 2020).

Berdasarkan masalah yang telah diuraikan diatas, peneliti ingin membuat aplikasi berbasis mobile android dengan memanfaatkan teknologi Virtual Tour yang diharapkan dapat meningkatkan nilai promosi dan daya tarik pengunjung, serta memperkenalkan Islamic Center dari luar kabupaten Tulang Bawang Barat secara virtual berupa obyek video panorama 360, melalui aplikasi yang dinamakan "Virtual Tour Islamic Center Tulang Bawang Barat". Metode pengembangan pada penelitian ini menggunakan Multimedia Development Life Cycle $(M D L C)$ model Luther. Sedangkan untuk pengujian sistem, peneliti menggunakan Standard Kualitas International Organization of Standardzation (ISO) 25010, adapun aspek yang akan diuji yaitu aspek Functional Suitability, aspek Operability, aspek dan Transferability. Kelebihan dari aplikasi “Virtual Tour Islamic Center" yaitu dimana visualisasinya seakan dapat di jelajahi seperti bentuk aslinya, dapat berjalan menelusuri ke segala arah, melihat dan memutar ke segala arah dan menjelajahi sekelilingnya sehingga pengguna aplikasi dapat menikmati suasana di Islamic Center yang sangat realistis. Dengan ini penulis mengusulkan penelitian yang berjudul "Aplikasi Virtual Tour Islamic Center Berbasis Android", yang diharapkan dapat menjadi altermatif media promosi yang menarik dan interaktif.

\section{TELAAH PUSTAKA \\ Game}

Game berasal dari bahasa inggris yang berarti permainan. Permainan adalah kegiatan yang didalamnya terdapat peraturan untuk menjalankan permainan. Sebuah permainan adalah sistem dimana pemain terlibat konflik buatan, disini pemain birenteraksi dengan sistem dan konflik dalam permainan merupakan rekayasa atau buatan (Wahyu Pratama, 2014). 


\section{Multimedia Development Life Cycle}

Multimedia Development Life Cycle (MDLC) adalah model proses pengembangan sistem untuk multimedia yang memiliki tujuan mengembangkan sebuah media pembelajaran yang lebih menarik dan efisien, dimana metode ini memiliki 6 tahapan, yaitu concept, design, material collecting, assembly, testing dan distribution

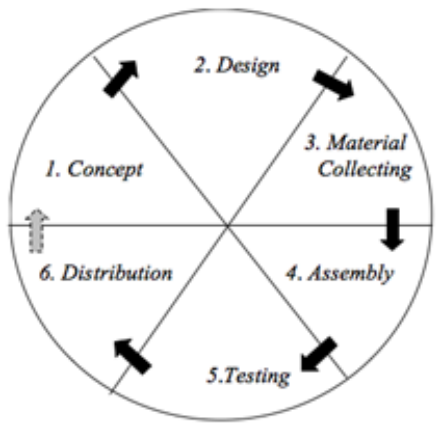

Gambar 1 Diagram Multimedia Development Life Cycle

\section{METODE PENELITIAN}

\section{Metode Analisis}

Analisis penting dilakukan dalam menyusun sebuah penelitian, agar dapat mengidentifikasi persoalanpersoalan yang akan muncul pada saat pembuatan aplikasi. Tahapan perencanaan ini dilakukan agar pembuatan aplikasi tidak terjadi kesalahan-kesalahan yang berarti dan agar aplikasi dapat diselesaikan sesuai waktu yang telah ditentukan. Dalam tahap analisis ini akan meliputi analisis sistem, analisis permasalahan dan analisis kebutuhan sistem, lokasi penelitian, informan penelitian.

\section{Analisis Sistem}

Analisis sistem yang akan dilakukan adalah dengan mengidentifikasi apa saja yang bisa dilakukan oleh aplikasi agar dapat berjalan dengan baik dan sesuai dengan kebutuhan di Islamic Center Tulang Bawang Barat.

\section{Analisis Permasalahan}

Media promosi yang digunakan di Islamic Center Tulang Bawang Barat pada umumnya menggunakan modul brosur, dan iklan banner. Selama ini calon pengunjung cenderung belum memahami bentuk visual dari Islamic CenterTulang Bawang Barat. Dari permasalahan tersebut maka peneliti bermaksud untuk membuat suatu aplikasi Virtual Tour menggunakan Unity 3D yang tentunya dapat menjadi media promosi baru bagi Islamic Center Tulang Bawang Barat.

\section{Hasil Dan Pembahasan}

\subsection{Tahapan Pengembangan}

Penelitian ini dilakukan mengikuti tahapan pengembangan Multimedia Development Life Cycle yang terdiri dari enam tahap, yaitu concept, design, obtaining material collecting, assembly, testing, dan distribution (Sutopo, 2003).

\subsubsection{Penyusunan Konsep (Concept)}

Membangun aplikasi Virtual Tour Islamic Center Tulang Bawang Barat, ada beberapa konsep yang dilakukan yaitu dengan menentukan maksud, tujuan, dan sasaran sistem dengan cara menganalisa kebutuhan dari aplikasi. Pada tahap ini ditentukan tujuan dari pembuatan aplikasi, pengguna. Tujuan dari aplikasi ini adalah merancang Aplikasi Virtual Tour secara interaktif dan menarik. Berikut adalah deskripsi dari konsep aplikasi Virtual Tour : 
Tabel 2.1 Deskripsi Konsep Aplikasi Virtual Tour

\begin{tabular}{|l|l|}
\hline Judul & Aplikasi Virtual Tour Islamic Center Tulang Bawang Barat \\
\hline Genre & Aplikasi Pariwisata \\
\hline Platform & Android \\
\hline $\begin{array}{l}\text { Software } \\
\text { Development }\end{array}$ & Unity3D \\
\hline $\begin{array}{l}\text { Target } \\
\text { Audiens }\end{array}$ & Pengunjung umum \\
\hline Pengguna & 1 Pengguna \\
\hline Objek & 3 video panorama \\
\hline
\end{tabular}

\subsection{Perancangan (Design)}

Perancangan atau design merupakan tahapan pembuatan spesifikasi pembuatan arsitektur program yang akan dibuat termasuk gaya, tampilan, dan kebutuhan material atau bahan untuk program. Pada tahap perancangan ini berupa perancangan storyboard dan perancangan flowchart.

\subsubsection{Perancangan Storyboard}

Storyboard merupakan deskripsi tiap tampilan (scene) dengan mencantumkan semua obyek ke scene sesuai alur cerita dari deskripsi aplikasi yang akan dirancang. Secara umum rancangan Storyboard yang akan dirancang peneliti dalam media promosi Virtual Tour sebagai berikut.

Tabel 2. Storyboard aplikasi

\begin{tabular}{|c|c|c|c|}
\hline Scene & Nama & Desain & Keterangan \\
\hline 1 & Splash Screen & & 1. Logo Unity \\
\hline 2 & Menu Utama & & Nama Aplikasi \\
\hline & & 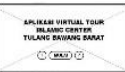 & - Gambar ! latar belakang \\
\hline & & & $\begin{array}{l}\text { - } \quad \text { Tombol menu info aplikasi } \\
\text { - } \quad \text { Tombol menu bantuan }\end{array}$ \\
\hline 3 & Menu Mulai & $\odot$ & $\begin{array}{l}\text { Tombol kembali untuk ke menu } \\
\text { utama }\end{array}$ \\
\hline 4 & Menu info aplikasi & & Tombol kembali ke menu utama \\
\hline 5 & Menu bantuan & 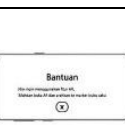 & $\begin{array}{l}\text { Tombol kembali kembali menu } \\
\text { Utama }\end{array}$ \\
\hline
\end{tabular}

\subsubsection{Perancangan Flowchart}

Flowchart menggambarkan tahapan proses dari awal hingga akhir. Berikut ini adalah flowchart aplikasi Virtual Tour : 


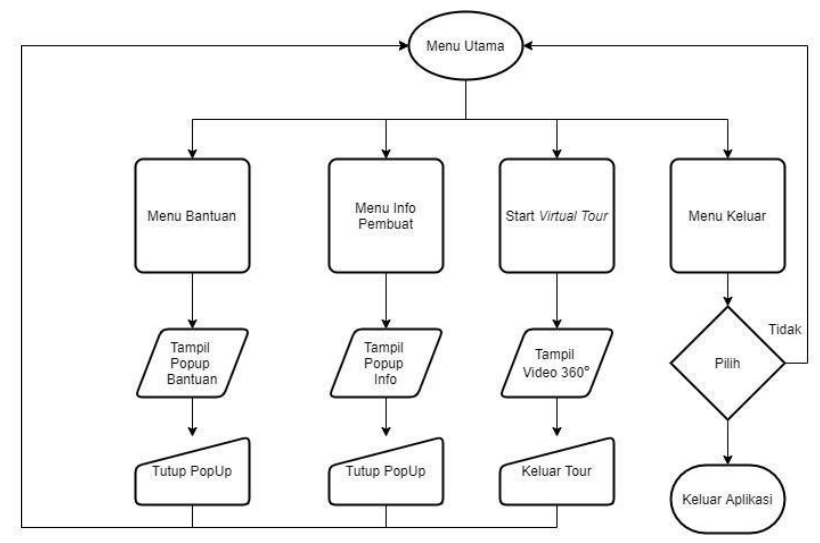

Gambar 2. Perancangan flowchart sistem

\subsection{Pengumpulan Bahan Material (Material Collecting)}

Pada tahap ini material yang diperlukan peneliti terkait pembangunan aplikasi Virtual tour seperti gambar, suara, background dan lain-lain. Bahan - bahan diperoleh dari berbagai sumber internet, dan hasil buatan peneliti. Berikut adalah rincian bahan material yang akan digunakan.

\subsubsection{Bahan Teks}

Bahan teks berupa jenis tulisan yang digunakan dalam pembuatan aplikasiVirtual Tour, dapat ditunjukan pada tabel 2.3.

Tabel 3. Bahan Teks

\begin{tabular}{|l|l|l|}
\hline No & Judul Teks & Jenis Font \\
\hline 1 & Judul & Swis27BTBold \\
\hline 2 & Tombol Menu Kamera AR & Swis27BT \\
\hline 3 & Tombol Menu Info Aplikasi & Swis27BT \\
\hline 4 & Tombol Menu Bantuan & Swis27BT \\
\hline 5 & Tombol Menu Keluar & Swis27BT \\
\hline 6 & Tombol Iya dan Tidak pada menu Keluar & Swis27BT \\
\hline 7 & Tombol Menu Kembali & Swis27BT \\
\hline
\end{tabular}

\subsubsection{Bahan Gambar}

Bahan gambar merupakan gambar-gambar yang dibutuhkan dalam pembuatan aplikasi, seperti dapat ditunjukan pada tabel 4

Tabel 4. Bahan Gambar

\begin{tabular}{|l|l|l|l|}
\hline No & \multicolumn{1}{|c|}{ Gambar } & Format & \multicolumn{1}{c|}{ Sumber } \\
\hline 1 & Background & .JPG & Dibuat di Adobe Adobe CC \\
\hline 2. & Tombol Mulai & .png & Dibuat di Adobe Photoshop CC \\
\hline 3 & Tombol lain & .png & www.freepik.com dan di edit di Adobe Photoshop \\
\hline
\end{tabular}

\subsubsection{Bahan Suara}

Bahan suara di dapat dari suara vokal yang ditelah direkam sebagai narator informasi mengenai objek, bahan suara ditunjukkan pada tabel 5 .

Tabel 5. Bahan Suara

\begin{tabular}{|l|l|l|l|}
\hline No & Nama Suara & Format & Sumber \\
\hline 1 & Backsound musik &.$m p 3$ & www.youtube.com \\
\hline 2 & Tour Guide &.$m p 3$ & Rindu Roro Rembulan \\
\hline
\end{tabular}

\subsection{Pembuatan Aplikasi (Assembly)}


Pada tahap ini, perancangan yang sudah dilakukan kemudian diimplementasikan menjadi aplikasi secara utuh. Pengkodean pada aplikasi ini menggunakan software Unity dan bahasa pemrograman C\#.

1. Halaman Utama

Pada tampilan halaman utama terdapat tombol tentang (!) untuk menampilkan info dari penulis, tombol bantuan (?) untuk menampilkan penjelasan singkat penggunaan aplikasi, tombol Start untuk memulai Virtual Tour dan tombol keluar aplikasi.

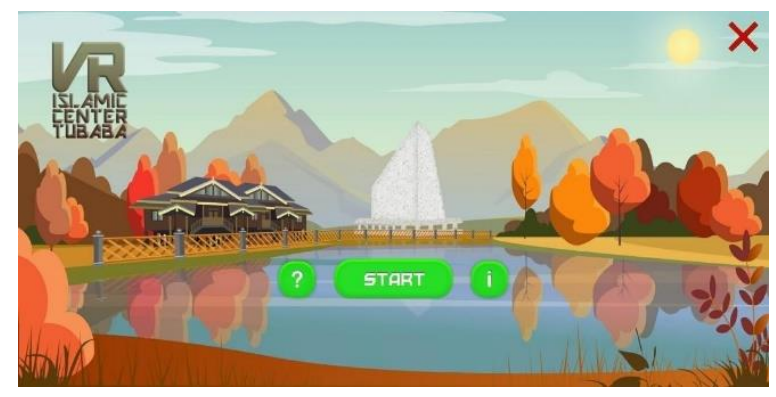

Gambar 3. Halaman utama aplikasi Virtual Tour Islamic Center Tulang Bawang Barat.

\section{Halaman Virtual Tour}

Halaman Virtual Tour akan tampil ketika tombol Start pada halaman utama ditekan. Pada halaman Virtual Tour terdapat beberapa tombol sepertI tombol keluar tour untuk kembali ke halaman utama dan pin lokasi untuk berpindah lokasi.

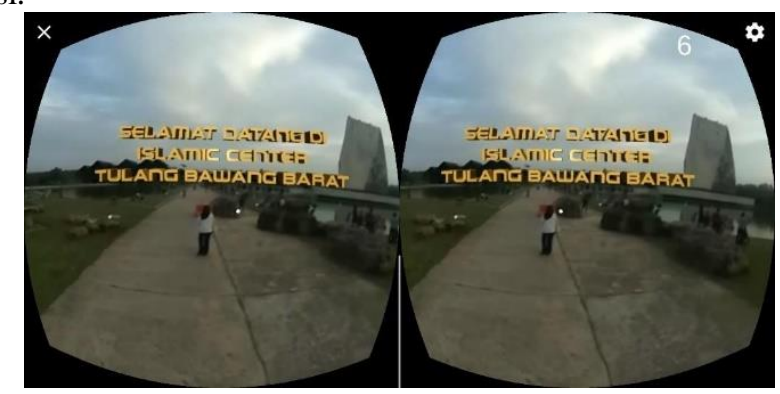

Gambar 4. Halaman Virtual Tour

3. Halaman Bantuan

Halaman bantuan akan muncul ketika user menekan tombol “?” pada halaman utama. Pada halaman bantuan terdapat cara penggunaan tombol navigasi aplikasi. Terdapat tombol silang pada halaman bantuan. Tombol silang pada halaman bantuan akan menutup halaman dan kembali ke halaman utama.

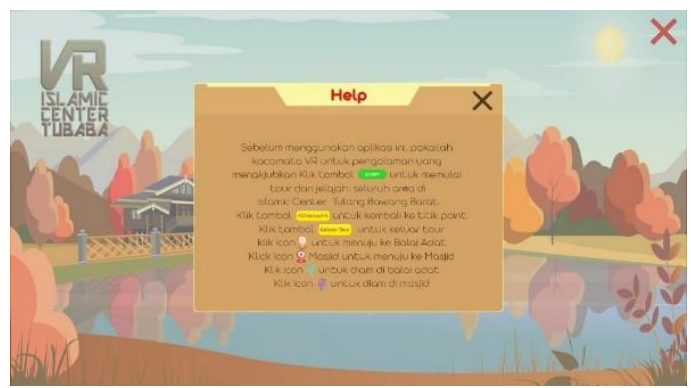

Gambar 5. Halaman Bantuan 


\section{Halaman Tentang}

Halaman tentang akan muncul ketika user menekan tombol tombol "!" pada halaman utama. Pada halaman tentang terdapat informasi tentang penulis. Terdapat tombol silang pada halaman bantuan. Tombol silang pada halaman bantuan akan menutup halaman dan kembali ke halaman utama.

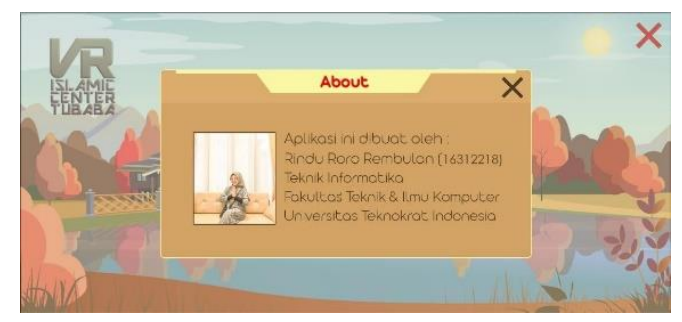

Gambar 6. Halaman Tentang

\section{Halaman Keluar Aplikasi}

Halaman keluar aplikasi akan muncul ketika user menekan tombol tombol " $\mathrm{X}$ " berwarna merah pada halaman utama. Pada halaman keluar aplikasi terdapat dua (2) tombol yaitu tombol YES untuk keluar aplikasi dan tombol $N O$ untuk kembali ke halaman utama.

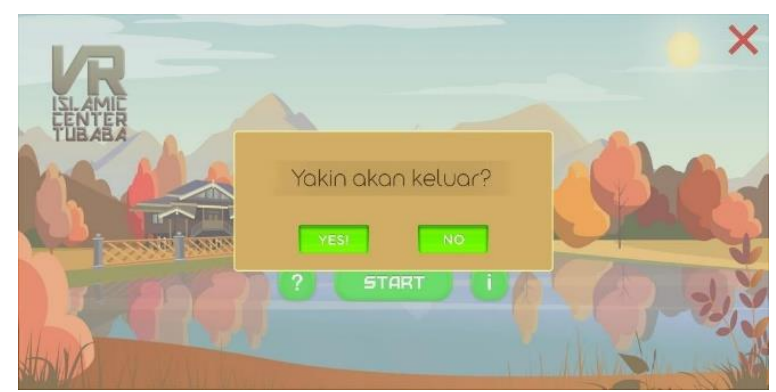

Gambar 7. Halaman Keluar Aplikasi

\section{Pengujian (Testing)}

Skenario pengujian aplikasi ini menggunakan standar kualitas ISO 25010. Untuk mengukur kualitas suatu aplikasi yaitu Functional Suitability, Operability, Transferability, dan Performance efficiency. Berikut ini daftar yang digunakan dalam penelitian.

\subsection{Aspek Functional Suitability}

Untuk pengujian aspek Functional Suitability menggunakan kuisioner yang berisi daftar fungsi yang dimiliki aplikasi. Kuisioner ini diisi oleh orang bisa menggunakan dan mengerti tentang aplikasi Virtual Tour Islamic Center. Daftar dapat dilihat dari tabel 6

Tabel 6. Pernyataan aspek Functional Suitability

\begin{tabular}{|c|c|c|}
\hline No & Kriteria & Pernyataaan \\
\hline 1. & \multirow{4}{*}{ Appropriateness } & Menampilkan halaman menu tama \\
\hline 2. & & Ketika tombol Start ditekan, akan menampilkan halaman Virtual Tour \\
\hline 3. & & $\begin{array}{l}\text { Ketika tombol info aplikasi ditekan, akan Menampilkan popup info pembuat } \\
\text { aplikasi }\end{array}$ \\
\hline 4. & & Ketika tombol bantuan ditekan, akan menampilkan popup bantuan \\
\hline
\end{tabular}




\begin{tabular}{|c|c|c|}
\hline 5. & & $\begin{array}{l}\text { Ketika tombol keluar tour pada halaman Virtual Tour ditekan, akan kembali } \\
\text { ke halaman menu utama }\end{array}$ \\
\hline 6. & & $\begin{array}{l}\text { Ketika tombol kembali pada popup Info Aplikasi ditekan, maka akan kembali } \\
\text { ke halaman menu utama }\end{array}$ \\
\hline 7. & & $\begin{array}{l}\text { Ketika tombol kembali pada popup bantuan ditekan, maka akan kembali ke } \\
\text { halaman menu utama }\end{array}$ \\
\hline 8. & & Aplikasi akan keluar ketika tombol YA pada popup keluar ditekan \\
\hline 9. & Accuracy & $\begin{array}{l}\text { Akan kembali ke menu utama ketika tombol TIDAK pada popup keluar } \\
\text { ditekan }\end{array}$ \\
\hline & & Akan menuju ke Masjid 99 Cahaya ketika pin lokasi berwarna merah ditekan \\
\hline 11. & & Akan menuju ke Balai Sesat Agung ketika pin lokasi berwarna kuning ditekan \\
\hline 12. & Compliance & $\begin{array}{l}\text { Akan menuju ke checkpoint/Pemilihan lokasi ketika tombol checkpoint } \\
\text { ditekan }\end{array}$ \\
\hline 13. & Accuracy & $\begin{array}{l}\text { Menampilkan lokasi yang sesuai ketika pin lokasi berwarna ditekan (Contoh } \\
\text { : Masjid } 99 \text { Cahaya / Balai sesat Agung) }\end{array}$ \\
\hline 14. & Compliance & Memutar suara ketika Virtual Tour dimulai \\
\hline
\end{tabular}

Berdasarkan hasil pengujian Functional Suitability pada tabel diatas, maka presentasi uji aspek Functional Suitability dapat dihitung sebagai berikut :

$$
\begin{gathered}
\text { Persentase Functional Suitability }=\frac{\text { skor hasil pengujian }}{\text { skor tertinggi }} \times 100 \% \\
\text { Sukses }=\frac{14}{14} \times 100 \%=100 \%
\end{gathered}
$$

Dari hasil perhitungan persentase uji aspek Functional Suitability di atas, sehingga dapat disimpulkan dalam aspek Functional Suitability aplikasi Virtual Tour Islamic Center Tulang Bawang Barat memperoleh hasil nilai $100 \%$ dan artinya aplikasi dapat bekerja dengan baik

\subsection{Aspek Operability}

Untuk pengujian aspek Operability di penelitian ini menggunakan kuisioner yang diisi oleh umum atau masyarat. Berikut daftar bisa dilihat pada tabel 7.

Tabel 7. Pernyataan aspek Operability

\begin{tabular}{|c|c|c|}
\hline No & Kriteria & \\
\hline 1. & & Pernyataaan \\
\cline { 1 - 1 } 2. & \multirow{2}{*}{ Appropriateness Recognisability } & Aplikasi ini dapat mengenalkan Islamic Center dengan baik. \\
\cline { 3 - 3 } & &
\end{tabular}




\begin{tabular}{|c|c|c|}
\hline 3. & & $\begin{array}{l}\text { Secara keseluruhan aplikasi Virtual Tour ini sesuai untuk } \\
\text { gunakan dalam media promosi Islamic Center }\end{array}$ \\
\hline 4. & \multirow{4}{*}{ Learnability } & $\begin{array}{l}\text { Mudah untuk menggunakan aplikasi Virtual tour } \\
\text { Islamic Center }\end{array}$ \\
\hline 5. & & $\begin{array}{l}\text { Saya belajar untuk menggunakan aplikasi ini dengan cepat } \\
\text { Virtual Tour Islamic Center }\end{array}$ \\
\hline \multirow[b]{2}{*}{7.} & & $\begin{array}{l}\text { Saya dapat menggunakan aplikasi Virtual Tour Islamic Center } \\
\text { tanpa instruksi tertulis }\end{array}$ \\
\hline & & $\begin{array}{llll}\begin{array}{l}\text { Secara keseluruhan aplikasi pariwisata ini mudah untuk } \\
\text { dipelajari }\end{array} & & & \\
\end{array}$ \\
\hline 8. & \multirow{4}{*}{ Ease of use, Helpfulness } & $\begin{array}{l}\text { Cara menggunakan aplikasi Virtual Tour Islamic Center } \\
\text { sederhana }\end{array}$ \\
\hline 9. & & 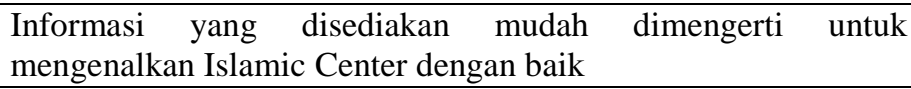 \\
\hline 10 & & Informasi dalam aplikasi mudah untuk dipahami. \\
\hline 11. & & $\begin{array}{l}\text { Secara keseluruhan, saya puas dengan kemudahan penggunaan } \\
\text { aplikasi pariwisata ini. }\end{array}$ \\
\hline 12. & \multirow[t]{5}{*}{ Attaractiveness } & $\begin{array}{l}\text { Tampilan aplikasi Virtual Tour Islamic Center ini meyenangkan } \\
\text { dan menarik }\end{array}$ \\
\hline 13. & & $\begin{array}{l}\text { Aplikasi Virtual Tour Islamic Center dapat merespon dengan } \\
\text { baik }\end{array}$ \\
\hline 14. & & Kesesuaian background halaman menu utama bagus \\
\hline 15. & & Kesesuaian warna pada aplikasi bagus \\
\hline 16. & & $\begin{array}{l}\text { Secara keseluruhan, aplikasi Virtual Tour Islamic Center ini } \\
\text { menarik }\end{array}$ \\
\hline
\end{tabular}

Perhitungan skor berdasarkan kriteria penilaian dan kategori penilaian diperoleh dari:

Skor Aktual = Jumlah Responden $x$ Bobot Nilai

Skor Ideal $=$ Jumlah Responden $\mathrm{x}$ Total Bobot Nilai

Total Skor $=($ Jumlah Skor Aktual $\div$ Jumlah Skor Ideal $) \times 100$

Berikut merupakan hasil perhitungan skor 5 kriteria penilaian dari 15 responden yaitu :

Tabel 8. Perhitungan aspek Operability

\begin{tabular}{|c|c|c|c|c|c|c|c|c|c|c|c|c|c|c|c|c|c|c|c|}
\hline \multirow{3}{*}{ Kriteria Jawaban } & \multirow{3}{*}{ ВОВОт } & \multicolumn{17}{|c|}{ Pernyataan } & \multirow{3}{*}{ Total Nilai } \\
\hline & & \multicolumn{4}{|c|}{ Appropriateness Recognisability } & \multicolumn{4}{|c|}{\begin{tabular}{|c|} 
Learnability \\
\end{tabular}} & \multicolumn{4}{|c|}{ Ease of use dan Helpfulness } & \multicolumn{5}{|c|}{ Attractiveness } & \\
\hline & & Soal l & Soal 2 & Soal 3 & Soal 4 & Soal 5 & Soal 6 & \begin{tabular}{|l|} 
Soal 7 \\
\end{tabular} & Soal 8 & Soal 9 & Soal 10 & Soal 11 & Soal 12 & Soal 13 & Soal 14 & Soal 15 & Soal 16 & \begin{tabular}{|l|} 
Soal 17 \\
\end{tabular} & \\
\hline SS & 5 & 11 & 8 & 8 & 6 & 13 & 9 & 13 & 12 & 12 & 14 & 12 & 14 & \begin{tabular}{|l|}
8 \\
\end{tabular} & 12 & 12 & 11 & 9 & 920 \\
\hline SS & 4 & 4 & 7 & 7 & 9 & 2 & 6 & 2 & 3 & 3 & 1 & 3 & 1 & 7 & 3 & 3 & 4 & 6 & 284 \\
\hline $\mathrm{N}$ & 3 & 0 & 0 & 0 & 0 & 0 & 0 & 0 & 0 & 0 & 0 & 0 & 0 & 0 & 0 & 0 & 0 & 0 & 0 \\
\hline TS & 2 & 0 & 0 & 0 & 0 & 0 & 0 & 0 & 0 & 0 & 0 & 0 & 0 & 0 & 0 & 0 & 0 & 0 & 0 \\
\hline STS & 1 & 0 & 0 & 0 & 0 & 0 & 0 & 0 & 0 & 0 & 0 & 0 & 0 & 0 & 0 & 0 & 0 & 0 & 0 \\
\hline \multicolumn{2}{|l|}{ Skor Aktual } & 71 & 68 & 68 & 66 & 73 & 69 & 73 & 72 & 72 & 74 & 72 & 74 & 68 & 72 & 72 & 71 & 69 & 1204 \\
\hline \multicolumn{2}{|l|}{ Skor Ideal } & 75 & 75 & 75 & 75 & 75 & 75 & 75 & 75 & 75 & 75 & 75 & 75 & 75 & 75 & 75 & 75 & 75 & 1275 \\
\hline \multicolumn{19}{|l|}{ Total Skor } & $94 \%$ \\
\hline
\end{tabular}

Berdasarkan hasil rata-rata per-aspek penilaian kuesioner menunujukkan nilai rata-rata untuk semua pernyataan adalah sebesar 94\%. Dari hasil tersebut jika dibandingkan dengan interprestasi skala likert, maka artinya aplikasi ini memperoleh nilai sangat baik dalam aspek Operability atau aplikasi Virtual Tour Islamic Center Tulang Bawang Barat dapat dipahami, dipelajari, digunakan dan menarik bagi pengguna aplikasi.

\section{Aspek Transferability}


Untuk pengujian aspek Transferability akan diuji pada beberapa perangkat mobile berbasis android dengan spesifikasi perangkat keras dan perangkat lunak yang berbeda di setiap perangkat. Adapun tujuan dari pengujian ini adalah untuk mengetahui apakah ada kendala pada aplikasi jika digunakan pada perangkat yang lain.

Tabel 9. Pernyataan aspek Transferability

\begin{tabular}{|c|c|c|}
\hline No & Kriteria & Pernyataaan \\
\hline 1. & & $\begin{array}{l}\text { Aplikasi Virtual Tour Islamic Center dapat digunakan pada jenis perangkat } \\
\text { smartphone berbeda }\end{array}$ \\
\hline 2. & Adaptability & $\begin{array}{l}\text { Aplikasi Virtual Tour Islamic Center dapat dapat digunakan pada jenis sistem } \\
\text { operasi android yang berbeda }\end{array}$ \\
\hline 3. & \multirow{3}{*}{ Installability } & Aplikasi Virtual Tour Islamic Center dapat diinstall dengan mudah \\
\hline 4. & & Instalasi aplikasi Virtual Tour Islamic Center berjalan dengan baik \\
\hline 5. & & Proses instalasi aplikasi berjalan normal \\
\hline 6. & $\begin{array}{l}\text { Transferability } \\
\text { compliance }\end{array}$ & $\begin{array}{l}\text { Apakah aplikasi Virtual Tour Islamic Center dapat diinstall pada smartphone } \\
\text { berbeda }\end{array}$ \\
\hline
\end{tabular}

Berdasarkan hasil pengujian Transferability pada tabel diatas, maka presentasi uji aspek Transferability dapat dihitung sebagai berikut :

$$
\begin{gathered}
\text { Persentase Transferability }=\frac{\text { skor hasil pengujian }}{\text { skor tertinggi }} \times 100 \% \\
\text { Sukses }=\frac{6}{6} \times 100 \%=100 \%
\end{gathered}
$$

Dari hasil perhitungan persentase uji aspek Transferability di atas, sehingga dapat disimpulkan dalam aspek Transferability aplikasi Virtual Tour Islamic Center Tulang Bawang Barat memperoleh hasil nilai 100\% dan artinya aplikasi dapat digunakan pada device yang berbeda. Berikut merupakan daftar device yang di uji.

Tabel 10. Daftar hasil pengujian pada beberapa device

\begin{tabular}{|c|l|l|c|c|}
\hline No & Nama Device & \multicolumn{1}{|c|}{ Versi OS } & RAM & Waktu Eksekusi \\
\hline 1. & Oppo F1f & Android 5.1.1 (Lollipop) & $2 \mathrm{~Gb}$ & 1,71 detik \\
\hline 2. & Oppo A37 & Android 5.1 (Lollipop) & $3 \mathrm{~Gb}$ & 1,5 detik \\
\hline 3. & Redmi 4x & Android 6.0.1 (Marshmello) & $4 \mathrm{~Gb}$ & 1,4 detik \\
\hline 4. & Google Pixel & Android 7.1 (Nougat) & $3 \mathrm{~Gb}$ & 1,38 detik \\
\hline 5. & Oppo A5s & Android 8.1 (Oreo) & $4 \mathrm{~Gb}$ & 1,22 detik \\
\hline 6. & Redmi note 7 & $\begin{array}{l}\text { Android } 9 \\
\text { (Pie) }\end{array}$ & $4 \mathrm{~Gb}$ & 1,14 detik \\
\hline
\end{tabular}




\begin{tabular}{|c|l|l|c|c|}
\hline 7. & Vivo Y20 & Android 9 (Pie) & $4 \mathrm{~Gb}$ & 1 detik \\
\hline 8. & Vivo Y12 & $\begin{array}{l}\text { Android 9 } \\
(\text { Pie })\end{array}$ & $4 \mathrm{~Gb}$ & 1 detik \\
\hline 9. & Oppo A53 & Android 10 & $2 \mathrm{~Gb}$ & 1 detik \\
\hline 10. & Oppo A92 & Android 10 & $4 \mathrm{~Gb}$ & 1 detik \\
\hline 11. & Samsung M30S & Android 10 & $4 \mathrm{~Gb}$ & 1 detik \\
\hline 12. & Redmi note 9 & Android 10 & $4 \mathrm{~Gb}$ & 0,9 detik \\
\hline 13. & $\begin{array}{l}\text { Redmi Note 9 } \\
\text { Pro }\end{array}$ & Android 9 (Pie) & $6 \mathrm{~Gb}$ & 0,82 detik \\
\hline 14. & Poco X3 & Android 10 & & 0,7 detik \\
\hline
\end{tabular}

Berdasarkan hasil pengujian yang dilakukan pada beberapa device berbasis android, maka perhitungan rata-rata waktu eksekusi adalah sebagai berikut.

$$
\begin{aligned}
& \text { Rata }- \text { Rata waktu eksekusi }=\frac{\text { Jumlah waktu eksekusi }}{\text { Jumlah perangkat }} \\
& \text { Rata }- \text { Rata waktu eksekusi } \\
& =\frac{(1,71+1,5+1,4+1,38+1,22+1,14+1+1+1+1+1+0,9+0,82+0,7)}{14} \\
& =1,0364 \text { detik }
\end{aligned}
$$

Berdasarkan perhitungan rata-rata waktu eksekusi diatas diperoleh hasil 1.0364 detik.

\section{SIMPULAN}

Pembangunan aplikasi Virtual Tour Islamic Center Tulang Bawang Barat yang dibuat berplatform android. Aplikasi Virtual Tour Islamic Center Tulang Bawang Barat ini dibuat menggunakan Unity 3D dan untuk video $360^{\circ}$ berupa visual dari Islamic Center Tulang Bawang Barat diambil menggunakan Kamera Theta+ dan diedit menggunakan aplikasi Vegas Pro. Aplikasi Virtual Tour diharapan dapat menjadi media alternatif baru yang menarik dan interaktif untuk mempromosikan tempat pariwisata Islamic Center Tulang Bawang Barat. Aplikasi Virtual Tour Islamic Center Tulang Bawang Barat sudah diuji menggunakan ISO 25010, yang mana aspek yang diuji adalah aspek Functional Suitability mendapatkan skor 100\%, aspek Operability mendapatkan skor 94\% dan aspek Transferability mendapatkan skor $100 \%$ serta waktu rata-rata eksekusi 1,0364 detik. Dari keseluruhan pengujian ISO 25010 mendapatkan skor total rata-rata 95\% atau mempunyai skala sangat baik.

\section{UCAPAN TERIMA KASIH}

Puji syukur penulis panjatkan kepada Tuhan YME, karena atas berkat dan rahrnat-Nya, penulis dapat menyelesaikan Penelitian dengan judul "Pencarian Mobil Travel Berbasis Android Menggunakan Metode Auto Sugges".Penulis juga mengucapkan terima kasih kepada:

1. Dr. H.M. Nasrullah Yusuf, S.E., M.B.A. selaku Rektor Universitas Teknokrat Indonesia. 
2. Dr. H. Mahathir Muhammad, S.E., M.M. selaku Dekan Fakultas Teknik dan Ilmu Komputer Universitas Teknokrat Indonesia.

3. Ibu Dyah Ayu Megawaty, M.Kom., selaku Ketua Program Studi S1 Informatika Fakultas Teknik dan Ilmu Komputer Universitas Teknokrat Indonesia.

\section{REFERENSI/DAFTAR PUSTAKA}

Arifatno, D. R., \& Rahmadi, H. (2017). Perancangan Aplikasi Gerakan Shalat Menggunakan Augmented. Seminar Nasional Teknologi Informasi dan Komunikasi (SeNTIK) STMIK Jakarta STI\&K, 115.

H. Wattiheluw, F., Rochimah, S., \& Fatichah, C. (2019). Klasifikasi Kualitas Perangkat Lunak Berdasarkan ISO/IEC 25010 Menggunakan Fuzzy Mamdanidan PSO untuk Situs Web E-Commerce. Jurnal Ilmiah Teknologi Informasi, XVII(01), 73-83.

Islamic Center Kebanggaan Masyarakat Tubaba. (2019, September 9). Diambil kembali dariKominfo Tulang Bawang Barat: https://kominfo.tulangbawangbaratkab.go.id/islamic-canter-kebangaan- masyarakat-tubaba/

Juansyah, A. (2015, Agustus a). Pembangunan Aplikasi Child Trake Berbasis Assisted - Global Positioning System (A-GPS) Dengan Platform Android. Jurnal Ilmiah Komputer dan Informatika, I, 2-3.

Kemendikbud. (2020, Agustus 02). Aplikasi. Diambil kembali dari KBBI: https://kbbi.kemdikbud.go.id/entri/aplikasi

Kurniawan, I., Setiawansyah and Nuralia (2020) 'PEMANFAATAN TEKNOLOGI AUGMENTED REALITY UNTUK PENGENALAN PAHLAWAN INDONESIA DENGAN MARKER', Jurnal Informatika dan Rekayasa Perangkat Lunak, 1(1), pp. 9-16.

Mahendra, i. B. (2016). IMPLEMENTASI AUGMENTED REALITY (AR) MENGGUNAKAN

UNITY 3D DAN VUPORIA SDK . Jurnal Ilmu Komputer , 2.

Maulana, A., Rosalina, V., \& Safaah, E. (2020, Maret). Implementasi Teknologi Virtual Tour Perpustakaan Menggunakan Metode Pengembangan Multimedia Develpment Life Cycle (MDLC). Jurnal Sistem Informasi, 7, 1.

Putra, D. M. (2017). Pemanfaatan Engine Vuforia untuk Implementasi Teknologi Augmented Reality Berbasis Mobile . Journal Of Information and Teknology, 71.

Pasaribu, A. F. O. et al. (2019) 'Sistem Informasi Geografis untuk Pencarian Lokasi Bengkel Mobil di Wilayah Kota Bandar Lampung', Jurnal Tekno Kompak, 13(2), pp. 1-6.

Putra, A. D. (2020) 'RANCANG BANGUN APLIKASI E-COMMERCE UNTUK USAHA PENJUALAN HELM', Jurnal Informatika dan Rekayasa Perangkat Lunak, 1(1), pp. 17-24.

Rahman, F. (2020). Sekretariat Islamic Center Tubaba. (R. R. Rembulan, Pewawancara) Solikin, I. (Tahun 2018, Mei). Implementasi Penggunaan Smartphone Android Untuk Control PC. Jurnal Pengembangan IT, 3.

Sintaro, S., Ramdani, R. and Samsugi, S. (2020) 'Rancang Bangun Game Edukasi Tempat Bersejarah Di’, 1(1), pp. 51-57.

Sugiyono. (2013). Metode Penelitian Kuantitatif, Kualitatif Dan R\&D. Bandung: Cv.Alfabeta.

Sutopo, A. H. (2003). Multimedia Interaktif dan Flash. Yogyakarta: PT Graha Ilmu.

Tian, J. (2005). SOFTWARE QUALITY ENGINEERING. Dalam V. Moliere (Penyunt.), TESTING, QUALITY ASSURANCE, AND QUANTIFIABLE IMPROVMENT. Canada: John Wiley \& Sons, Inc., Hoboken, New Jersey.

Wicaksono, A. Y., Rismanto, R., \& Prasetyo, A. (2017, February). Pengembangan Aplikasi Sistem Informasi Rekomendasi Tempat Wisata di Kota Batu Menggunakan Metode Electre. Jurnal Informatika Polinema, 3, 32.

Yuliana, A., \& Lisdianto, E. (2017, Februari). Aplikasi Virtual Tour Sebagai Media Promosi Objek di Stone Garden Kabupaten Bandung Barat. Jurnal Ilmiah Management Informatika dan Komputer, 01(01), 19. 